\title{
Effects of Psyching-Up on Sprint Performance
}

\author{
Sarra Hammoudi-Nassib, ${ }^{1,2}$ Sabri Nassib, ${ }^{1,2}$ Moktar Chtara, ${ }^{1,2}$ Walid Briki, ${ }^{3}$ \\ Anis Chaouachi, ${ }^{1,4}$ David Tod, ${ }^{5}$ and Karim Chamari ${ }^{1,6}$ \\ ${ }^{1}$ Tunisian Research Laboratory "Sports Performance Optimization" National Center of Medicine and Science in Sports (CNMSS), \\ Tunis, Tunisia; ${ }^{2}$ University of Manouba, ISSEP Ksar Saîd, Tunis, Tunisia; ${ }^{3}$ Sport Science Program, College of Arts and Sciences, \\ Qatar University, Doha, Qatar; ${ }^{4}$ AUT University, Sports Performance Research Institute New Zealand, Auckland, New Zealand; \\ ${ }^{5}$ Department of Sport and Exercise Science, Aberystweyth University, Aberystweyth, Wales, United Kingdom; and ${ }^{6}$ Aspetar, \\ Research and Education Center, Aspetar Qatar Orthopedic and Sports Medicine Hospital, Doha, Qatar
}

\begin{abstract}
Hammoudi-Nassib, S, Nassib, S, Chtara, M, Briki, W, Chaouachi, A, Tod, D, and Chamari, K. Effects of psyching-up on sprint performance. J Strength Cond Res 31(8): 2066-2074, 2017The present research aimed at examining whether the psyching up (PU) strategies improve performance in 30-m sprinting. Sixteen male sprinters (age, $20.6 \pm 1.3$ years; body mass, $77.5 \pm 7.1 \mathrm{~kg}$; height, $180.8 \pm 5.6 \mathrm{~cm}$ ) participated in this study. Before each experimental session, the Hooper index was used to monitor the subject's feeling for the quality of sleep of the previous night, perceived quantity of stress, delayed onset muscle soreness, and fatigue. After completing general and specific warm-up, participants had to rate their degree of self-confidence. Then, they were asked to follow 1 of these 4 conditions: Imagery (experimental PU condition), Preparatory arousal (experimental PU condition), Attention placebo (control condition), and Distraction (control condition) during the final 30 seconds of the rest period right before performing a 30-m sprint. Participants separately and randomly performed all conditions. Results showed that although the imagery and preparatory arousal strategies contributed to increase the performance in the short-distance sprints (from 0 to $10 \mathrm{~m}$ ), the imagery strategy contributed to increase the performance in the $30-\mathrm{m}$ sprints. These findings support the general view that the PU strategies could improve athletic performance.
\end{abstract}

KEY WoRDS cognitive strategies, imagery, preparatory arousal, velocity, sprinting

\section{INTRODUCTION}

$\mathrm{I}$ $\mathrm{t}$ is common that athletes use precompetitive strategies to enhance their performance. These strategies, called psyching up (PU) strategies, have elicited the sport psychologists' interest because authors showed their impact on sport performance $(8,13,16,27,33,35,37,39)$.

Address correspondence to Anis Chaouachi, anis.chaouachi@email.ati.tn. $31(8) / 2066-2074$

Journal of Strength and Conditioning Research

(C) 2014 National Strength and Conditioning Association
Athletes can use a large range of behavioral or cognitive techniques designed to psych themselves up. More specifically, researchers have found that PU may increase the muscular endurance $(8,16,37)$, strength $(4,13,27,35,37,39)$, power $(8,30,38)$, acceleration $(11,16)$, and athletic performance $(1,11,16,17,31)$. The effects of the PU strategies on the maximal strength and local muscular endurance during simple or isolated dynamic contraction would result from a series of factors that may be classified as having central, peripheral, and mechanical influences (17). However, although the effect of PU strategies on the performance to simple tasks is now well documented $(8,13,16,27,33,35,37,39)$, the effect of these strategies on the actual athletic performance has received limited empirical attention. The purpose of the present study was to examine the effect of PU strategies on the actual athletic performance.

Some authors displayed the effects of PU strategies on athletic performance $(16,31)$. However, their findings revealed differences. Studies found that only the Imagery (i.e., visualizing oneself performing a task as best of one's ability) (16) or Preparatory arousal (i.e., charging up for maximum performance by getting made, aroused, and pumped up) (16) was associated with higher levels of grip strength, although these 2 PU strategies have been identified by other authors as the most effective PU strategies in enhancing strength performance $(4,13,27,35,37,39)$. However, these studies present 2 major limitations. First, they generally used untrained samples of individuals when investigating the PU effect on the strength production, where the PU effect was often robust (7). Thus, it is not clear whether PU has a beneficial effect for trained individuals $(7,31,32)$. Second, research was generally focused on simple task performance (e.g., handgrip, leg extension, bench press, sit-ups, press ups, pull-ups, and the standing broad jump) as experimental tasks $(7,8,13)$.

Based on the athletic performance over 60 and 100 yards, Caudill et al. (8) found that when participants used the Preparatory arousal, Attentional focus, and Self-efficacy strategies, participants recorded higher levels of performance than when they used the Distraction and Attention placebo. This

2066 Journal of Strength and Conditioning Research 
indicates a significant PU main effect with faster running times. However, the study by Caudill et al. (8) used sprint distances that most athletes rarely use in real competitions. In constrast, rugby union players, for example, sprint over $1-20 \mathrm{~m}$ and do not reach top speeds $(11,12)$. For most team-sport athletes, acceleration has more influence on performance than top speed. Research examining the influence of $\mathrm{PU}$ on acceleration and sprint performance over short distances, which replicate actual distances covered in a game, will extend knowledge and yield information to help athletes.

Consequently, both to generalize any conclusions about the PU effect on performance and to apply findings to real competitive situations, the present research did take into account all of these limitations in (a) using samples of athletes, who are trained individuals; (b) focusing on the actual athletic performance; and (c) using short sprint distances. Indeed, a large range of sport competitions, such as soccer, rugby, athletic races, rowing, and the like, require high levels of strength production and acceleration. For example, some authors showed that the strongest athletes are the most effective in sprinting $(1,10,11,21,40)$. This reinforces the necessity to focus on the actual athletic performance and short sprint distances. Moreover, the present study also attempted to compare the strategies of imagery and preparatory arousal-which have been recommended as important strategies in enhancing performance in a number of previous studies $(8,13,16,27,31,35,37,39)$-to shed the light about their potential effects on the actual athletic performance (15).

The present study used the $30-\mathrm{m}$ sprint as study context in this experiment because (a) it is representative of sprint distances covered during competition in multiple sports (e.g., soccer, rugby), (b) it mainly requires high levels of strength $(1,21,31)$ and acceleration $(11,16)$, (c) it is a compound sportspecific skill regularly trained to improve athletic performance and then related to success $(3,6,11,12)$, and (d) it lends itself well for rigorous analyses. Indeed, in the present study, the performance was analyzed in examining distinct phases into the $30-\mathrm{m}$ sprint, which is subdivided into initial acceleration phase $(0-10 \mathrm{~m})$ and phase of maximum speed. Regarding the hypotheses, it was expected that the use of these PU strategies right before the $30-\mathrm{m}$ short sprints (i.e., experimental task) should increase the performance on these sprints in comparison with the control conditions because it was shown that the imagery and preparatory arousal strategies increased the strength production $(13,16,39)$.

\section{Methods}

\section{Experimental Approach to the Problem}

To determine whether PU strategies may be effective to improve $30-\mathrm{m}$ sprint performance using a withinparticipants design, a randomized experimental design was used. To address the hypothesis that the PU should have a significant effect on 30-m sprint performance, the current within-subject study examined the effects of different strat- egies used during the $30-\mathrm{m}$ sprint performance. Before each $30-\mathrm{m}$ sprint test, participants engaged in 1 of 4 interventions. The interventions were counterbalanced and randomized on separate days to avoid any order effect. These experimental conditions included 2 psych-up conditions (i.e., imagery and preparatory arousal conditions) and 2 control conditions (i.e., attention-placebo control and distraction conditions). Subjects were asked to engage in the control condition to prevent them from psyching up (33).

\section{Subjects}

The protocol of the study was approved by the Ethic Committee of the National Center of Medicine and Science in Sports of Tunisia before the commencement of the assessments. Each participant signed an informed consent before taking part in the study. Sixteen male sprinters (age, $20.6 \pm 1.3$ years; body mass, $77.5 \pm 7.1 \mathrm{~kg}$; height, $180.8 \pm$ $5.6 \mathrm{~cm}$ ) competing at a regional level volunteered to participate in this study. They were sports science students pursuing degrees in exercise science and physical education at the University of Manouba, Tunis. Their average experience was $7.2 \pm 1.7$ years, and the average of their weekly training duration was between 6 and 8 hours. Before the experiment, none of the subjects had ever specifically performed PU with the aim of improving motor performance. Therefore, they were given detailed instructions to perform PU strategies and control conditions accurately and efficiently. At the completion of the sessions, participants engaged in 1 of the 4 conditions in a counterbalanced, randomized order. No information about the purposes of the study was given to the subjects until after they completed the experiment.

\section{Psyching up Conditions}

In the imagery condition, subjects had to imagine that they were performing trials as best they could with their performances improving over each trial. They received the following instructions, which were based on previous research $(31,39)$ :
You have $30 \mathrm{~s}$ during which I would like you to visualize yourself performing sprints as best you can. Please, close your eyes and imagine yourself doing sprint as fast as possible. Visualize yourself setting a new personal best on each trial.

On the other hand, in the preparatory arousal condition, subjects had to be in aroused position. They received the following instructions, again based on previous research (31):

You have $30 \mathrm{~s}$ during which I would like you to "emotionally charge-up." Psych yourself up for maximum performance by getting mad, aroused, pumped-up, and charged-up.

\section{Control Conditions}

In the attention-placebo control, subjects were asked to focus on and estimate their own heart rate. They were then 
TABLE 1. Test-retest reliability of tests.*

\begin{tabular}{|c|c|c|c|}
\hline Criterion measures & $\mathrm{ICC}_{3.1}(95 \% \mathrm{Cl})$ & SEM & CV\% \\
\hline Overall sprint $0-30 \mathrm{~m}$ & $0.960(0.915-0.985)$ & 0.02 & 2.60 \\
\hline Acceleration $0-10 \mathrm{~m}$ & $0.919(0.828-0.969)$ & 0.02 & 4.62 \\
\hline Maximal-velocity $10-30 \mathrm{~m}$ & $0.957(0.908-0.983)$ & 0.02 & 3.35 \\
\hline
\end{tabular}

given standardized instructions and verbal encouragements to perform to the best of their ability. Before being tested, the athletes were given the same breakfast, consisting of 1 cake, a glass of orange juice, and water, which was maintained during the period of the protocol to be under the same test conditions for not obtaining misleading results. The experiment included 2 phases followed by a final debriefing. The first phase was a familiarization phase, whereas the second phase corresponded to the experimental sessions.

Familiarization Phase. This phase familiarized subjects with the experimental material and informed them about the experiment methodological details. This session was treated as a control day in which the subjects performed a maximal sprint. The subjects were not asked to use any specific psychological intervention during the control day. Subjects were instructed that the experiment included 4 sessions separated each other by 48 hours and that each session included a series of sprint of $30 \mathrm{~m}$ after a warming up. They were also asked to avoid high-intensity physical training for 24 hours before testing. This aimed to prevent the influence of residual fatigue from interfering with the test performance.

You have 30 -sec during which I would like you to count backward out loud from 1,000 in groups of 7; for example, 1,000; $993 ; 986 ; 979 \ldots$ and so on.

\section{Procedures}

During all the experimental sessions, the athletes were asked to wear the same shoes on each testing day, and they were

TABLE 2. Comparison between scale scores before each intervention.*

\begin{tabular}{lc}
\hline Variable & $\begin{array}{c}\text { ANOVA repeated measure } \\
(p \text { value })\end{array}$ \\
\hline Sleep & $1.01(0.40)$ \\
Fatigue & $1.65(0.21)$ \\
Stress & $1.45(0.24)$ \\
Muscle & $1.44(0.25)$ \\
$\quad$ soreness & \\
RPE & $2.24(0.10)$ \\
SES & $1.47(0.24)$ \\
\hline
\end{tabular}

${ }^{*}$ ANOVA $=$ analysis of variance; RPE $=$ rating perceived effort; SES = self-efficacy scale.
Experimental Phase. Upon their arrival, subjects started a standardized warming up including 3 steps (34). First, subjects performed a 5-minute self-paced jog or run general warm-up followed by 4 minutes of active rest, which consisted of walking on the track. Second, subjects completed the dynamic stretching warming up during 15-17 minutes. Third, subjects performed incremental intermittent sprints during 5 minutes.

After the warming up, subjects performed 2 baseline (preintervention) test measures of 30-m sprints on an indoor track (10-mm thickness tartan track, Mondo SportFlex; Mondo America, Inc., Summit, NJ, USA) as baseline measure before the experimental test. Then, subjects received a specific instruction, delivered according to the assigned condition, and they were asked to achieve as best they could for the sprints of $30 \mathrm{~m}$.

During each phase, the same researchers were present throughout the tests. All tests were conducted at the same time of the day for each subject (between 09:30 AM and 11:00 AM), to avoid any diurnal variation, and under standardized environmental conditions $\left(24 \pm 1^{\circ} \mathrm{C}\right.$ of temperature and $43 \pm 2 \%$ of relative humidity). No medical problem appeared during the study. 
TABLE 3. Data illustrating the effect of sprint performances, condition, and interaction.

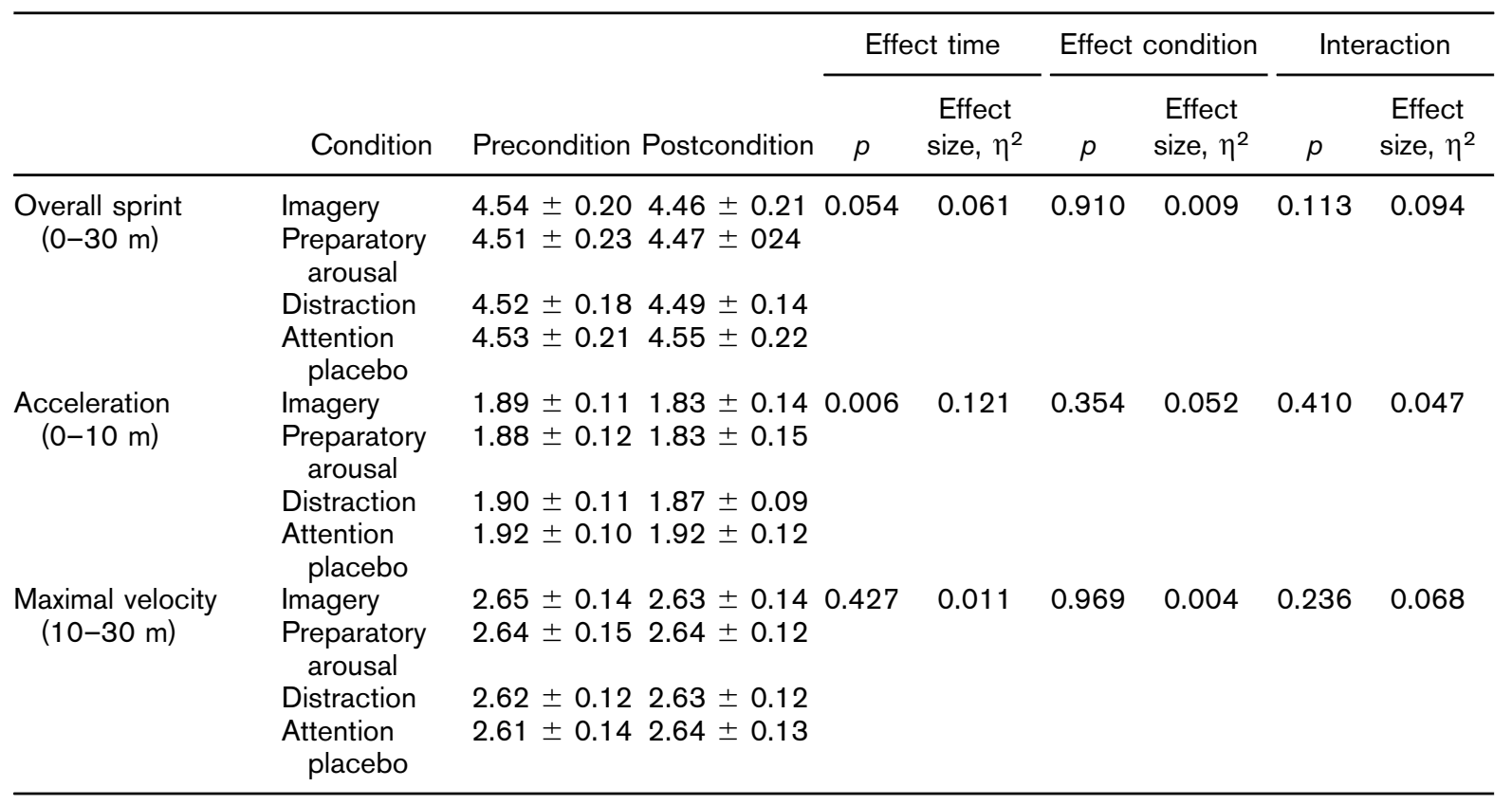

Final Debriefing. Subjects were debriefed about the goal of the study once all experimental sessions were finished. Moreover, subjects received their own performance results of each test performed during the study.

\section{Measures}

Subjective rating of stress, fatigue, muscles soreness, and last night's sleep: Before each experimental session, subjects had to record subjective rating of stress, fatigue, muscles soreness, and last night's sleep (18) on a scale of 1-7 from "very very low or good" (point 1) to "very very high or bad" (point 7), point 4 being "average." These rating scales has previously been shown to provide an efficient means to monitoring both overtraining and staleness (18).

Self-Efficacy Scale. Before the PU condition, subjects had to rate their degree of confidence by recording a number from 0 to 100 using the self-efficacy scales (SES) (2). This consists of recording the strength of their efficacy beliefs on a 100point scale, ranging in 10-unit intervals from 0 ("Cannot do"), through intermediate degrees of assurance, 50 ("Moderately certain can do"), to complete assurance, 100 ("Highly certain can do").

Performance. Straight running sprint was assessed using photocell beams (Brower Timing Systems, Salt Lake City, UT, USA; accuracy of 0.01 seconds) set at $50-\mathrm{cm}$ height at 0 , 10,20 , and $30 \mathrm{~m}$ from the starting line. The subjects started when ready after having obtained from the experimenter a period of maximum 5 seconds to start whenever they felt free for doing so. Subjects started from a standing start $0.5 \mathrm{~m}$ behind the first timing gate, thus avoiding triggering the electronic gate prematurely with any move of the lower or upper limbs. The start of the sprint was taken in a consistent order and at the sound of the experimenters. Acceleration was assessed for a distance of $10 \mathrm{~m}$, with the players beginning in a stationary position. Maximal velocity was recorded for the last $20 \mathrm{~m}$ of the $30-\mathrm{m}$ sprint. Total $30-\mathrm{m}$ performance was also considered.

Rating Perceived Effort. After the completion of the experimental test, the rating perceived effort (RPE) scale (14) was used to rate the subjects' perceived effort. A rating of 0 was associated with no perceived effort (rest), and a rating of 10 was considered to be maximal perceived effort and associated with the most stressful exercise ever performed.

\section{Statistical Analyses}

Before using parametric tests, the assumption of normality was verified using Kolmogorov-Smirnov test. Reliability of the measures (between each of the baseline measures of sprint phase performance during the 4 conditions) was assessed with a Cronbach's model interclass correlation coefficient (ICC) via 1-way analysis of variance (ANOVA), with a value of $0.7-0.8$ being questionable and 0.9 indicating high reliability (36), and the SEM according to the method of Hopkins (19). To determine possible main effects of 
TABLE 4. The precision of the predicted increase from baseline to peak of each psyching up protocol on each of the dependent variables.

\begin{tabular}{|c|c|c|c|c|c|c|c|c|}
\hline & \multirow[b]{2}{*}{ Condition } & \multirow{2}{*}{$\begin{array}{c}\text { Mean } \\
\text { difference }\end{array}$} & \multicolumn{2}{|c|}{$\begin{array}{l}95 \% \\
\text { Confidence } \\
\text { limits }\end{array}$} & \multirow{2}{*}{$\begin{array}{c}\text { Cohen's } \\
d\end{array}$} & \multicolumn{2}{|c|}{$\begin{array}{l}\text { Likelihood of exceeding } \\
\text { smallest worthwhile } \\
\text { change (\%) }\end{array}$} & \multirow{2}{*}{$\begin{array}{l}\text { No. subjects whose } \\
\text { performance is better than } \\
\text { the control session }\end{array}$} \\
\hline & & & Lower & Upper & & Higher Trivial & Detrimental & \\
\hline \multirow{4}{*}{$\begin{array}{l}\text { Overall sprint } \\
\quad(0-30 \mathrm{~m})\end{array}$} & Imagery & -0.079 & -0.148 & -0.011 & 0.39 & 87.4412 .46 & 0.10 & 14 \\
\hline & $\begin{array}{l}\text { Preparatory } \\
\text { arousal }\end{array}$ & -0.042 & -0.093 & 0.009 & 0.18 & 42.9256 .97 & 0.11 & 11 \\
\hline & Distraction & -0.030 & -0.108 & 0.048 & 0.17 & 43.8051 .58 & 4.62 & 8 \\
\hline & $\begin{array}{l}\text { Attention } \\
\text { placebo }\end{array}$ & 0.029 & -0.036 & 0.093 & 0.14 & 1.7664 .00 & 34.24 & 3 \\
\hline \multirow{4}{*}{$\begin{array}{l}\text { Acceleration } \\
(0-10 \mathrm{~m})\end{array}$} & Imagery & -0.066 & -0.138 & 0.007 & 0.58 & 88.7310 .27 & 1.00 & 12 \\
\hline & $\begin{array}{l}\text { Preparatory } \\
\text { arousal }\end{array}$ & -0.046 & -0.087 & -0.005 & 0.37 & 85.7714 .12 & 0.11 & 9 \\
\hline & Distraction & -0.032 & -0.080 & 0.016 & 0.30 & 68.1030 .33 & 1.57 & 8 \\
\hline & $\begin{array}{l}\text { Attention } \\
\text { placebo }\end{array}$ & -0.005 & -0.059 & 0.049 & 0.05 & 27.8755 .29 & 16.84 & 7 \\
\hline \multirow{4}{*}{$\begin{array}{l}\text { Maximal } \\
\quad \text { velocity } \\
(10-30 \mathrm{~m})\end{array}$} & Imagery & -0.014 & -0.039 & 0.011 & 0.10 & 12.6887 .16 & 0.15 & 7 \\
\hline & $\begin{array}{c}\text { Preparatory } \\
\text { arousal }\end{array}$ & 0.004 & -0.036 & 0.045 & 0.03 & 4.1586 .73 & 9.12 & 7 \\
\hline & Distraction & 0.002 & -0.035 & 0.039 & 0.02 & 7.5981 .67 & 10.74 & 7 \\
\hline & $\begin{array}{l}\text { Attention } \\
\text { placebo }\end{array}$ & 0.034 & -0.002 & 0.069 & 0.24 & 0.1036 .90 & 63.00 & 4 \\
\hline
\end{tabular}

psyching up, 2-way ANOVAs with repeated measures ( 4 conditions $\times 2$ time points) was used to determine if significant differences existed between the 4 conditions (i.e., imagery, preparatory arousal, distraction, and attention placebo) and testing (pre-psyching up and post-psyching up). When significant effects were present, Bonferroni post hoc analyses were performed. The effect size was calculated for all ANOVAs with the use of a partial $\eta^{2}(9)$. In addition to the comparison analyses, Cohen's $d$, smallest worthwhile change (SWC), and likelihood of clinical meaningfulness were calculated for 10-, 20-, and 30-m sprint distances (20). The Cohen's $d$ is calculated from the mean change divided by the $S D$ of the data; thresholds for qualitative descriptors of Cohen's $d$ were set at $<0.20$ as "trivial," 0.20 to $<0.50$ as "small," 0.50 to $<0.80$ as "moderate," and $\geq 0.80$ as "large" (9). The smallest change to be considered worthwhile (SWC) was thus calculated from 0.20 of the $S D$ of the data. The threshold of a clinical meaningful effect was set at $75 \%$ (20). The quantitative chances of beneficial effects were assessed qualitatively as follows: $<1 \%$, almost certainly not; 1 to $<5 \%$, very unlikely; 5 to $<25 \%$, unlikely; 25 to $<75 \%$, possible; 75 to $<95 \%$, likely; 95 to $<99$, very likely; and $\geq 99 \%$, almost certain. In addition, a 1-way ANOVA with repeated measures was used to examine the difference between scores of the scales before each intervention (fatigue, sleep, stress, muscle soreness, RPE, and SES). The results are expressed as means $\pm S D$ and $95 \%$ confidence intervals. Statistical significance was set at $p \leq 0.05$.

\section{Results}

\section{Preliminary Results}

Day-to-day ICC, as a test of reliability for the baseline measures of 0 - to $10-, 10$ - to $30-$, and 0 - to $30-\mathrm{m}$ sprint performance during 4 conditions, demonstrated a high level of reliability (range, 0.92-0.96) (Table 1).

\section{Analysis With Repeated Measures}

Psychological Variables. Repeated-measure ANOVA results revealed no significant difference between psychological variables (Table 2).

Dependant Variables. Pre- and posttest means for the dependent variables are presented in Table 3. Regarding the overall $30-\mathrm{m}$ sprint time, the ANOVA indicated a significant main effect of time $\left(F=3.88 ; p \leq 0.05 ; \eta^{2}=0.06\right)$ but indicated no significant main effect of condition $(F=0.18 ; p>0.05)$ and time $\times$ condition interaction $(F=0.11 ; p>0.05)$. Regarding the 0 - to 10 -m sprint time, a significant main effect of time $\left(F=8.28 ; p<0.01 \eta^{2}=0.12\right)$ was observed. However, there was no significant main effect of condition $(F=0.12 ; p>$ $0.05)$ and time $\times$ condition interaction $(F=0.98 ; p>0.05)$. For the 10 - to $30-\mathrm{m}$ sprint time, there was no significant effect of time $(F=0.64 ; p>0.05)$, condition $(F=0.08$; 


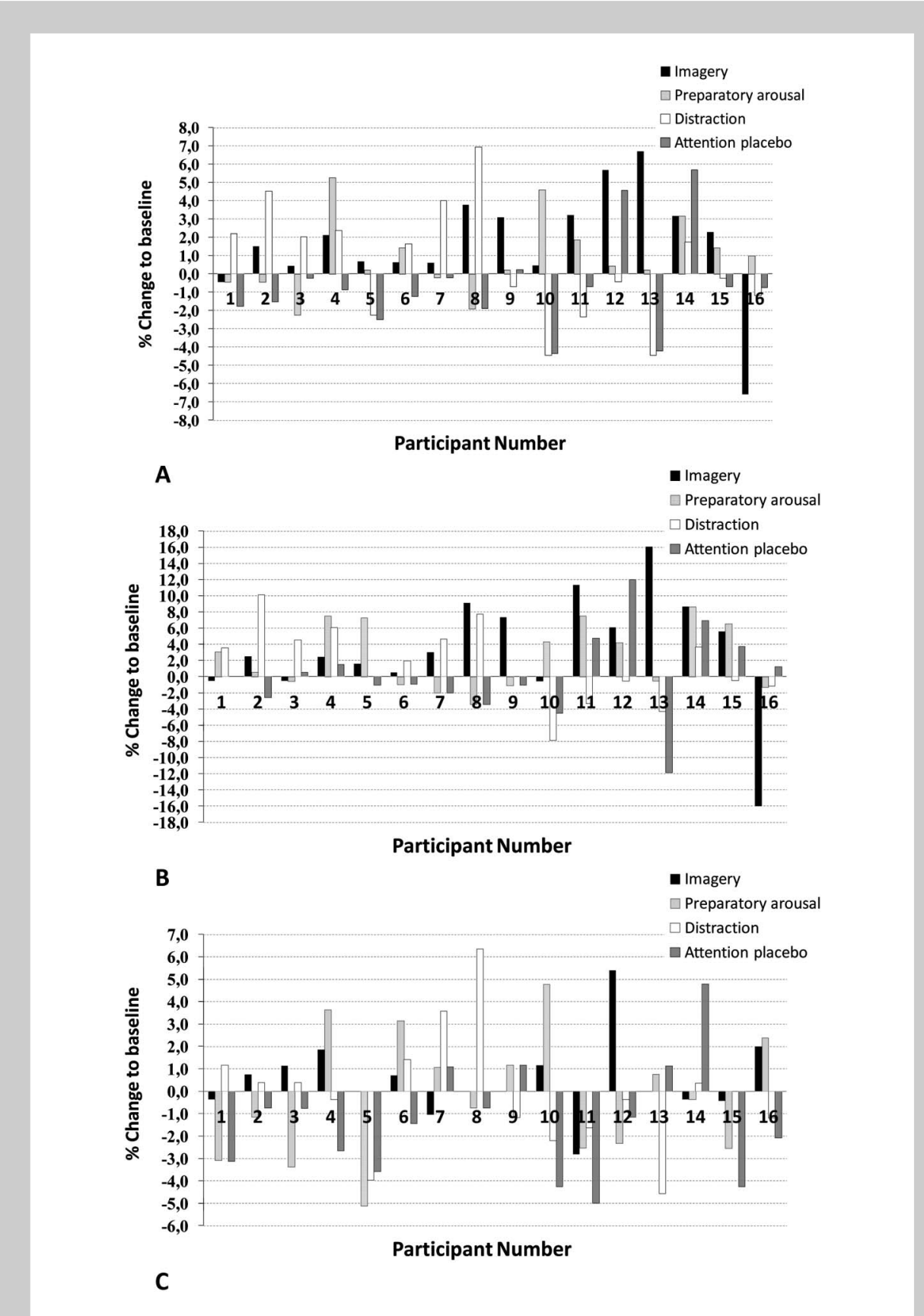

Figure 1. Individual performance changes compared with the baseline for each psyching up protocol for the overall sprint-time $(A)$, acceleration phase of the sprint $(B)$, and maximal velocity phase of the sprint $(C)$.

protocols elicited changes that had $>75 \%$ likelihood of exceeding the SWC $(88$ and $85 \%$, respectively; Table 4). The last $20 \mathrm{~m}$ of sprint (10 to $30 \mathrm{~m}$ ) was unaffected by any of the psyching up protocols with no protocol eliciting a $75 \%$ likelihood of exceeding the SWC compared with the control condition (Table 4).

\section{Individual Responses}

Figure 1 shows the results as a percentage of the baseline performance, with each baseline performance considered to be $100 \%$ of the individual's maximal performance (i.e., a sprint time of less than $100 \%$ represents an improved performance). It illustrates the individual changes of each subject for each phase of sprint and psyching up protocol (where no bar appears for a subject, this represents a $0 \%$ change). The graph illustrates that the range of responses by each individual varied between subjects, tests, and psyching up conditions used. There was a great consistency between the results of the overall sprint time and the phase of acceleration, with patterns emerging on the responders and nonresponders to the psyching up protocols. For the overall sprint time, most subjects responded positively after imagery, distraction, and preparatory arousal protocols. Participant 14 had large positive responses after all psyching up protocols, especially the imagery and

$p>0.05)$, and time $\times$ condition interaction $(F=1.46$; $p>0.05)$.

\section{Magnitude-Based Inferences}

The PU condition that elicited a substantial likelihood of potentiating the overall $30-\mathrm{m}$ sprint time, of a substantial amount (i.e., had a $>75 \%$ of exceeding a small Cohen's $d$ ), was the imagery condition (Table 4 ). For the 0 - to $10-\mathrm{m}$ sprint time, both the imagery and preparatory arousal PU attention placebo, with improvements up to $5.7 \%$. However, there were also subjects who responded negatively to $\mathrm{PU}$ conditions. A $4.2-4.5 \%$ decreases in the overall sprint time was found for subjects 10 and 13 after the distraction and attention protocols. In the acceleration phase of the sprint, subjects 4 and 14 responded positively to all psyching up protocols (range of improvements: 1.5-8.7\%). Participant 13 responded largely negatively after attention-placebo protocol, with decreases up to $16 \%$. This negative response was 
also observed at participant $16(16 \%)$. In the maximal velocity phase of the sprint, there were also large individual responses.

\section{Discussion}

The purpose of the present study was to investigate whether $\mathrm{PU}$ is effective in enhancing sprint performance and to compare the effectiveness of 2 PU strategies: imagery and preparatory arousal. Focused on the sprint exercise, imagery condition was found to improve the performance of initial sprint acceleration $(0-10 \mathrm{~m})$ and overall sprint $(0-30 \mathrm{~m})$ compared with control conditions. Thus, evidence was brought that the PU strategies significantly enhanced short-distance sprinting performance.

The variance analyses showed that the performance in $30-\mathrm{m}$ sprint was particularly influenced by improvements in the acceleration (i.e., the first $10 \mathrm{~m}$ of sprint). Therefore, it seems that the possible improvements in force and power, already observed by previous studies, have improved the section of the sprint, where force is important (high muscular solicitation with relatively low speed for accelerating).

Attaining a high sprint velocity over a short distance is important for successful performance in a lot of sport (e.g., American football, rugby, soccer, Australian Rules football, etc) (26). This suggests that achieving a high running velocity in the first few meters of sprinting is crucial for successful acceleration during a short sprint. Therefore, as sprint performance is of great importance in many sports, with elite soccer players spending approximately $11 \%$ of the game sprinting, which equates to a 10 - to $15-\mathrm{m}$ sprint every 90 seconds approximately (3), with similar findings reported in rugby league $(6,22)$, rugby union $(11,12)$, and field hockey (28). As well, Stolen et al. (29) reported that during a 90minute game, numerous explosive bursts of activity are required, including sprinting.

Concerning the individual responses, most of the athletes had large positive responses, especially for the imagery and preparatory arousal strategies, with improvements up to $5.7 \%$. Thus, 14 of 16 athletes significantly decreased their $30-\mathrm{m}$ sprinting time after the imagery condition $(4.46 \pm 0.21$ seconds) as compared with the control condition (4.54 \pm 0.20 seconds).

This is explained by the impact of the PU strategies on performance-related effects and motivation, supporting the conceptual model of Paivio (23) predicting that in addition to its effects on performance, imaging also helps reducing anxiety and increase self-confidence and intrinsic motivation. There is also the possibility that improvements in the latter psychological variables could be the cause of the observed improvements in performance.

Accordingly, the neuromuscular feedback theory of Richardson (25) demonstrated that a vivacious and focused image produced muscle activation comparable to that observed in actual motion. In addition, the mental simulation is sufficiently high to generate proprioceptive feedback used to enhance corresponding motor program. Even though, the neurophysiological perspective of Brody et al. (7) suggested that PU might lead to changes in motor unit recruitment within the muscle. Specifically, it was hypothesized that there could be an increase in motor unit activation in the agonist muscle and a decrease in motor unit activation in the antagonist muscle. Self-directed cognitive strategies or psyching up do likely occur in the cerebral cortex. Therefore, psyching up may stimulate changes in the activity of central nervous system (CNS), resulting in adjustments in motor unit recruitment or synchronization or muscle firing rate or all. Similarly, changes in the CNS may modify sympathetic nervous system activity, which may result in alterations in peripheral factors like muscle contractility (5).

Eleven subjects significantly decreased their time in the preparatory arousal condition (4.47 \pm 0.24 seconds) as compared with the control condition $(4.51 \pm 0.23 \mathrm{sec}-$ onds), this finding differs from the results of Pierce et al. (24), who found that preparatory arousal led to higher strength performance compared with relaxation and control for a 1 repetition maximum (RM) bench press, whereas relaxation led to reduced strength performance for a $3 \mathrm{RM}$ bench press. The results also revealed that for the acceleration phase, subjects exhibited significantly better performances in both imagery and preparatory arousal condition compared with either the distraction or attention-placebo conditions. However, in many cases, the subjects experienced difficulty in correctly counting backward. This observation was reaffirmed in a postexperimental interview, where many of the subjects indicated that they became frustrated and upset with their inability to count backward correctly.

The present study protocol monitored the subjects' state when arriving at the laboratory for the experiment. Indeed, despite the randomization of the 4 conditions, one of these could have been biased by a different status of "fatigue" or "stress." Thus, the Hooper index was used to monitor the subjects feeling for the quality of sleep of the previous night and the perceived quantity of stress, delayed onset muscle soreness, and fatigue. The statistical analysis showed that these variables were not different across the 4 conditions. Thus, we can conclude that the improvements in sprint performance after PU conditions were probably caused by the condition itself and not any status of fatigue for the control conditions.

\section{Practical Applications}

The present study findings show that PU strategies can actually enhance short-distance sprinting performance as compared with the control conditions. Accordingly, this study investigated the effectiveness of imagery condition in improving sprint performance of initial sprint acceleration $(0-10 \mathrm{~m})$ and overall sprint $(0-30 \mathrm{~m})$ compared with distraction and attention-placebo conditions. Hence, the present results 
showed that the $30-\mathrm{m}$ sprint performance improvements resulted from the improvements in the acceleration (i.e., the first $10 \mathrm{~m}$ of sprint).

Then, the current study has provided evidence that PU may be beneficial even for subjects who never previously experienced any mental preparation. Moreover, the present study is the first to interpret the effect of PU strategies on different phases of sprint and to demonstrate that the improvement in performance was mostly observed during the initial sprint.

Therefore, the effectiveness of PU in enhancing shortdistance sprinting performance is vital for successful performance in sports, where short sprints are performed as in jumping in track and field.

Thus, the athletes felt that they were more able to perform cognitively the imagery condition better than other conditions, which were appraised more positively and which promoted feelings of confidence while performing sprint. From the results of this study, strength and conditioning practitioners should note that these findings highlight how essential it would be for field-sport athletes to incorporate $\mathrm{PU}$ into their sprint training workouts, which can then translate to more effective acceleration. In addition, it is advised that athletes must take full advantages of PU strategies during training and competition to enhance performance. Thus, performing appropriate PU strategies should be of paramount importance if coaches want to optimize their individual athlete's performance.

\section{ACKNOWLedGMents}

This study was financially supported by the Tunisian Ministry of Scientific Research, Technology and Development of Competency, Tunisia. The authors would like to thank Sabra Hammoudi Riahi who contributed in this research. They also acknowledge all the players and research support staff involved in this study for their input.

\section{REFERENCES}

1. Baker, D and Nance, S. The relationship between running speed and measures of strength and power in professional rugby league players. J Strength Cond Res 13: 230-235, 1999.

2. Bandura, A. Self-efficacy in Changing Societies. New York, NY: Cambridge University Press, 1995

3. Bangsbo, J, Mohr, M, and Krustrup, P. Physical and metabolic demands of training and match-play in the elite football player. J Sports Sci 24: 665-674, 2006.

4. Biddle, SJH. Mental preparation, mental practice and strength tasks: A need for clarification. J Sports Sci 3: 67-74, 1985.

5. Bray, JJ, Cragg, PA, MacKnight, ADC, and Mills, R. Lecture Notes on Human Physiology (3rd ed.). Oxford, CT: Blackwell Scientific Publications, 1994

6. Brewer, J and Davis, J. Applied physiology of rugby league. Sports Med 20: 129-135, 1995.

7. Brody, EB, Hatfield, BD, and Spalding, TW, et al. The effect of a psyching strategy on neuromuscular activation and force production in strength-trained men. Res $Q$ Exerc Sport 71: 162-70, 2000.

8. Caudill, D, Weinberg, RS, and Allen, J. Psyching-up and track athletes: A preliminary investigation. J Sport Psychol 5: 231-235, 1983.

9. Cohen, J. Statistical Power Analysis for the Behavioral Sciences. Hillside, NJ: LE Associates, 1988. pp. 23-97.

10. Cronin, JB and Hansen, KT. Strength and power predictors of sports speed. J Strength Cond Res 19: 349-357, 2005.

11. Cunniffe, B, Proctor, W, Baker, JS, and Davies, B. An evaluation of physiological demands of elite rugby union using global positioning system tracking software. J Strength Cond Res 23: 1195-1203, 2009.

12. Duthie, G, Pyne, D, Marsh, D, and Hooper, S. Sprint patterns in rugby union players during competition. J Strength Cond Res 20: 208-214, 2006.

13. Elko, $\mathrm{K}$ and Ostrow, AC. The effects of three mental preparation strategies on strength performance of young and older adults. J Sport Behav 15: 34-41, 2012.

14. Foster, C, Daines, E, Hector, L, Snyder, A, and Welsh, R. Athletic performance in relation to training load. Wis Med J 95: 370-374, 1996.

15. Geiger, PC, Cody, MJ, and Sieck, GC. Force-calcium relationship depends on myosin heavy chain and troponin isoforms in rat diaphragm muscle fibers. J Appl Physiol (1985) 87: 1894-1900, 1999.

16. Gould, D, Weinberg, RS, and Allen, J. Mental preparation strategies, cognitions, and strength performance. J Sport Psychology 2: 329-339, 1980.

17. Green, HJ. What do tests measure? In: Physiological Testing of the High-Performance Athlete (2nd ed.). J.D. MacDougall, H.A. Wenger, and H.J. Green, eds. Champaign, IL: Human Kinetics, 1991. 7-20.

18. Hooper, SL, Mackinnon, LT, Howard, A, Gordon, RD, and Bachmann, AW. Markers for monitoring overtraining and recovery. Med Sci Sports Exerc 27: 106-112, 1995.

19. Hopkins, WG. Measures of reliability in sports medicine and science. Sports Med 30: 1-15, 2000.

20. Liow, D and Hopkins, W. Velocity specificity of weight training for kayak sprint performance. Med Sci Sports Exerc 35: 1232-1237, 2003.

21. McBride, JM, Blow, D, Kirby, TJ, Haines, T, Dayne, AM, and Triplett, NT. Relationship between maximal squat strength and five, ten, and forty yard sprint times. $J$ Strength Cond Res 23: 1633-1636, 2009.

22. Meir, R, Newton, R, Curtis, E, Fardell, M, and Butler, B. Dopd. Physical fitness qualities of professional rugby league football players. J Strength Cond Res 15: 450-458, 2001.

23. Paivio, A. Cognitive and motivational functions of imagery in human performance. Can J Appl Sport Sci 10: 22S-28S, 1985.

24. Pierce, EF, McGowan, RW, and Eastman, NW. Effects of progressive relaxation on maximal muscle strength and power. J Strength Cond Res 7: 216-218, 1993.

25. Richardson, A. Mental practice: A review and discussion. Part I. Res Q 38: 95-107, 1967.

26. Rienzi, E, Drust, B, Reilly, T, Carter, JEL, and Martin, A. Investigation of anthropometric and work-rate profiles of elite South American international soccer players. J Sports Med Phys Fitness 40: $162-169,2000$.

27. Shelton, TO and Michael, JM. The content and effect of "psychingup" strategies in weight Lifters. Cogn Ther Res 2: 275-284, 1978.

28. Spencer, M, Lawrence, S, Rechichi, C, Bishop, D, Dawson, B, and Goodman, C. Time-motion analysis of elite field hockey, with special reference to repeated-sprint activity. J Sports Sci 22: 843-850, 2004.

29. Stolen, T, Chamari, K, Castagna, C, and Wisloff, U. Physiology of soccer: An update. Sports Med 35: 501-536, 2005. 
30. Theodorakis, Y, Weinberg, R, Natsis, P, Douma, I, and Kazakas, $\mathrm{P}$. The effects of motivational versus instructional self-talk on improving motor performance. Sport Psychol 14: 253-272, 2000.

31. Tod, D, Iredale, F, and Gill, N. Psyching-up and muscular force production. Sports Med 33: 47-58, 2003.

32. Tod, D, Iredale, KF, Michael, R, Mcguigan, D, Strange, EO, and Nicholas, G. Psyching-up enhances force production during the bench press exercise. J Strength Cond Res 19: 599-603, 2005.

33. Tod, D and McGuigan, M. The efficacy of psyching-up on strength performance. In: Focus on Exercise and Health Research. T.B. Selkirk, ed. New York, NY: Nova Science, 2006.

34. Turki, O, Chaouachi, A, Behm, DG, Chtara, H, Chtara, M, Bishop, D, Chamari, K, and Amri, M. The effect of warm-ups incorporating different volumes of dynamic stretching on 10- and 20-m sprint performance in highly trained male athletes. $J$ Strength Cond Res 26: 63-72, 2012.
35. Tynes, LL and Mcfatter, RM. The efficacy of psyching strategies on a weight-lifting task. Cogn Ther Res 11: 327-336, 1987.

36. Vincent, W. Statistics in Kinesiology. Champaign, IL: Human Kinetics, 2005.

37. Weinberg, RS, Daniel, G, and Allen, J. Effect of psyching-up strategies on three motor tasks cognition and motor performance. Cogn Ther Res 4: 1980.

38. Weinberg, RS, Jackson, A, and Seaboune, T. The effects of specific vs nonspecific mental preparation strategies on strength and endurance performance. $J$ Sport Beh 8: 175-180, 1985.

39. Whelan, JP, Epkins, CC, and Meyers, AW. Arousal interventions for athletic performance: Influence of mental preparation and competitive experience. Anxiety Res 2: 293-307, 1990.

40. Wisloff, U, Castagna, C, Helgerud, J, Jones, R, and Hoff, J. Strong correlation of maximal squat strength with sprint performance and vertical jump height in elite soccer players. Br J Sports Med 38: 285288, 2004. 